\title{
Systemic Treatment for Temporomandibular Joint Arthritis in Juvenile Idiopathic Arthritis
}
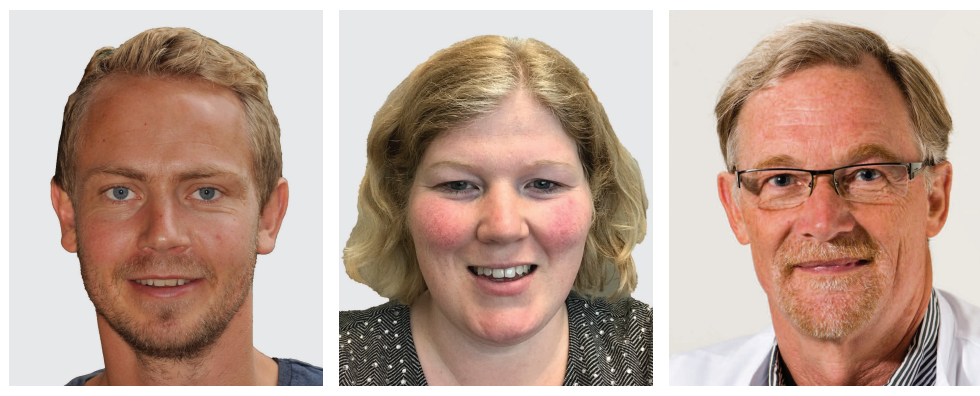

Within the last decade, intensified research has highlighted the orofacial consequences of juvenile idiopathic arthritis (JIA) involving the temporomandibular joint (TMJ). It has been documented that about $40 \%$ of subjects with JIA develop involvement of the $\mathrm{TMJ}^{1,2}$. Smaller studies have reported even higher frequencies of TMJ involvement ${ }^{3}$. TMJ arthritis may occur in otherwise quiescent JIA, and in rare cases the TMJ is the first and even the only joint involved ${ }^{2,4}$. It may lead to symptoms and dysfunction from both the joint and the muscles, with a significant effect on the quality of life $e^{1,2,5,6,7}$. In addition to facial signs and symptoms, the development of dentofacial deformity is a primary concern to patients with JIA 7 . The TMJ is considered a "vulnerable" joint to inflammation because of a superficially positioned intraarticular mandibular growth site of crucial importance for normal mandibular growth and development ${ }^{8}$. In skeletally immature patients, TMJ inflammation can affect the intraarticular growth site and disturb dentofacial growth and development ${ }^{7}$. The degree of dentofacial deformity depends on the timing of TMJ arthritis in relation to the general growth trajectory.

Research from the last decade has advanced our understanding of TMJ arthritis from JIA. The research progress indicates that TMJ involvement is a common finding in JIA $^{1,2,7}$. Arthritis-induced orofacial signs and symptoms may persist into adulthood in subjects with JIA and TMJ involvement ${ }^{9}$. Facial signs and symptoms correlate poorly with the severity of TMJ inflammation; contrast-enhanced magnetic resonance imaging (MRI) is therefore considered the gold standard for diagnosis of active TMJ inflammation ${ }^{10,11,12}$. Still, a standardized clinical examination is considered an important first-line, noninvasive assessment of dentofacial structures when conducted in combination with contemporary imaging and radiological examination standards ${ }^{7,12,13}$.
As the amount of TMJ-related research has increased, so has the confusion with the management of TMJ arthritis ${ }^{14}$. A part of this confusion originates from the use of inconsistent terminology across the research literature. Recently, interdisciplinary, consensus-based terminology was proposed to enhance communication across healthcare providers involved in the management of TMJ arthritis ${ }^{12}$.

An indisputable purpose of management is to address TMJ inflammation (defined as "TMJ arthritis"). Research has indicated that TMJ arthritis is a refractory condition that calls for an aggressive treatment approach ${ }^{2}$. No high-level evidence exists for the management of TMJ arthritis and the associated facial conditions. Importantly, well-treated patients with resolved TMJ inflammation may still have sequelae caused by previous TMJ arthritis (symptoms, dysfunction, and dentofacial deformity). This calls for a broader understanding of the concept of TMJ arthritis management. From a clinical perspective, optimal management of TMJ arthritis and the related sequelae can involve multidisciplinary efforts such as facial physiotherapy, TMJ arthrocentesis, orthopedic treatment with dental splints, and surgical interventions.

Traditionally, the application of intraarticular steroid (IAS) has been considered a safe and effective approach for management of TMJ arthritis in JIA ${ }^{15,16}$. The rationale for this approach has been extrapolated from the use of IAS in other joints in patients with JIA and from its use in adults with other temporomandibular disorders. It has been assumed that corticosteroids reduce TMJ arthritis, which in turn promotes normalization of facial growth and reduction in the progression of TMJ degeneration. However, recent research has challenged this assumption because the side effects may outweigh the beneficial properties related to this approach ${ }^{17}$. In skeletally immature subjects, IAS has been associated with suppression of mandibular growth and the

See TMJ MRI in JIA systemic treatment, page 909

Personal non-commercial use only. The Journal of Rheumatology Copyright (C) 2020. All rights reserved. 
development of intraarticular calcifications ${ }^{18,19}$. The intraarticular use of infliximab has been reported without any significant effects on TMJ arthritis ${ }^{19,20}$.

Evidence-based treatment aims to accumulate the best available evidence for clinical decision making. Unfortunately, little evidence exists. No contemporary human study, from within the biological era, has provided significant evidence to guide TMJ arthritis management. This leaves us with the question: how should we manage TMJ arthritis from JIA?

In this issue of The Journal, Bollhalder, et al ${ }^{21}$ address this question in a non-controlled retrospective study. The authors present longitudinal observational data from 38 consecutive patients with TMJ involvement receiving systemic immunosuppressive therapy. Methotrexate was administered in $92 \%$ and combined with biologics in $50 \%$ of the included subjects. The included patients were observed over a median period of 3.6 years (range 2.0-8.7 yrs). This observation represents the time between a baseline and a followup contrast-enhanced MRI examination. The results by Bollhalder, et al present evidence to suggest that systemic immunosuppressive management of TMJ arthritis (1) may reduce MRI-verified inflammation, (2) preserve osseous TMJ morphology, and (3) maintain normalized mandibular ramus growth over a period of at least 2 years. The results are subject to certain limitations that need careful consideration. This is also wisely addressed by the authors. Among others, it should be highlighted that only half of the patients were treatment-naive before baseline MRI examination. Also, the study does not clarify which systemic immunosuppressive drug is most effective for the treatment of TMJ arthritis.

However, despite the apparent limitations, the present study makes several noteworthy contributions to the existing literature concerning TMJ arthritis management:

- The results support the empirical practice that systemic medication can have a beneficial effect on TMJ inflammation. This may indicate that the TMJ is more susceptible to systemic medication than previously assumed ${ }^{2}$.

- Normalized mandibular ramus growth occurred in patients with baseline TMJ inflammation receiving systemic treatment. Interestingly, the mandibular growth did not correlate with the grade of baseline inflammation, indicating that normalized mandibular growth can occur despite the presence of TMJ inflammation. This brings up the relevant issue of whether we really have to strive toward complete resolution of TMJ inflammation or whether a mild grade of inflammation still allows for acceptable normalized mandibular growth.

- TMJ with baseline inflammation showed improvement in the severity of osseous TMJ deformity at followup after treatment with systemic immunosuppressive treatment. Bollhalder, et al found a weak negative correlation between the degree of baseline osseous TMJ deformity and mandibular growth ${ }^{21}$. This finding supports the assumption that TMJ osseous deformity may lead to increased joint friction and excessive joint loading, which in turn may lead to further TMJ deformity and mandibular growth retardation ${ }^{22}$. A potential implication of this finding is that TMJ deformity may have a greater influence on mandibular growth than previously assumed. Moreover, a clinical implication of this finding is that skeletally immature, well-treated patients in remission may still develop progressing dentofacial deformity because TMJ sequelae may further affect mandibular growth. The findings by the authors certainly provide incentive to further investigate the role of TMJ deformities in the development of dentofacial deformity in skeletally immature patients with JIA.

- The findings of Bollhalder, et a ${ }^{21}$ greatly contrast with the 2015 data presented by the same Zürich-based group reporting on the effects of IAS in TMJ ${ }^{18}$. In the 2015 study, 33 patients with TMJ arthritis from JIA received repeated IAS. The authors documented that greater exposure to IAS was correlated with increased TMJ deformity, development of intraarticular calcifications, and reduced mandibular growth $^{18}$. We can only agree with Bollhalder, et al that the present findings constitute a further argument against the use of IAS for TMJ arthritis because this approach holds potential risk for deterioration of TMJ deformity, potentially leading to further aggravation of the mandibular growth.

Interestingly, TMJ arthritis was the main indication for systemic immunosuppressive therapy in only 1 of the 38 patients included in the study presented by Bollhalder, et $a l^{21}$. A possible explanation is that oligoarticular extended and polyarticular JIA categories represented $58 \%$ of the included subjects. However, it may also be an indication that the TMJ is not greatly guiding treatment decisions. The optimistic findings by Bollhalder, et al certainly raise the question of whether the TMJ disease status should hold a more dominant role in clinical decision making.

This is the first study, to our knowledge, from the biologic era to report on the effect of systemic immunosuppressive treatment of TMJ arthritis from JIA. The apparent limitations to the retrospective study design restrict the generalizability of the findings at this point. However, the data generate new important questions and perspectives. Further research is warranted, and the authors should be complimented for an important contribution that indicates the direction for that future research. Bollhalder, et $a l^{21}$ leave an optimistic impression that needs further attention in future prospective, controlled trials with standardized followup. Finally, the authors leave us with the hope that the next decade will be the one in which we truly advance our understanding of the management of JIA-associated TMJ arthritis.

PETER STOUSTRUP $(1)$, DDS, PhD, Associate Professor, Section of Orthodontics, Aarhus University, Aarhus, Denmark;

Personal non-commercial use only. The Journal of Rheumatology Copyright @ 2020 . All rights reserved. 
MARINKA TWILT ${ }^{(1 D}$, MD, PhD,

Assistant Professor,

Cumming School of Medicine,

Alberta Children's Research Institute,

University of Calgary,

Alberta Children's Hospital,

Calgary, Alberta, Canada;

TROELS HERLIN (D), MD, DMSc,

Professor, Department of Pediatrics,

Aarhus University Hospital,

Aarhus, Denmark.

Address correspondence to Dr. P. Stoustrup, Section of Orthodontics, IOOS, Vennelyst Blvd. 9-11, 8000 Aarhus C, Denmark.

E-mail: pstoustrup@odont.au.dk

\section{REFERENCES}

1. Cannizzaro E, Schroeder S, Muller LM, Kellenberger CJ, Saurenmann RK. Temporomandibular joint involvement in children with juvenile idiopathic arthritis. J Rheumatol 2011;38:510-5.

2. Stoll ML, Sharpe T, Beukelman T, Good J, Young D, Cron RQ. Risk factors for temporomandibular joint arthritis in children with juvenile idiopathic arthritis. J Rheumatol 2012;39:1880-7.

3. Kuseler A, Pedersen TK, Gelineck J, Herlin T. A 2 year followup study of enhanced magnetic resonance imaging and clinical examination of the temporomandibular joint in children with juvenile idiopathic arthritis. J Rheumatol 2005;32:162-9.

4. Hugle B, Spiegel L, Hotte J, Wiens S, Herlin T, Cron RQ, et al. Isolated arthritis of the temporomandibular joint as the initial manifestation of juvenile idiopathic arthritis. J Rheumatol 2017;44:1632-5.

5. Frid P, Nordal E, Bovis F, Giancane G, Larheim TA, Rygg M, et al. Temporomandibular joint involvement in association with quality of life, disability, and high disease activity in juvenile idiopathic arthritis. Arthritis Care Res 2017;69:677-86.

6. Rahimi H, Twilt M, Herlin T, Spiegel L, Pedersen TK, Kuseler A, et al. Orofacial symptoms and oral health-related quality of life in juvenile idiopathic arthritis: a two-year prospective observational study. Pediatr Rheumatol Online J 2018;16:47.

7. Stoustrup P, Glerup M, Bilgrau AE, Küseler A, Verna C, Christensen $\mathrm{AE}$, et al. Cumulative incidence of orofacial manifestations in early juvenile idiopathic arthritis: a regional, three year cohort study. Arthritis Care Res 2019 Apr 11 (E-pub ahead of print).

8. Enlow DH, Hans MG, editors. Growth of the mandible. In: Essentials of facial growth. Philadelphia: Saunders; 1996:57-78.

9. Glerup M, Stoustrup P, Hauge L, Rypdal V, Nordal E, Frid P, et al. Long-term outcomes of temporomandibular joints in juvenile idiopathic arthritis. J Rheumatol 2019 Sep 15 (E-pub ahead of print).

10. Koos B, Twilt M, Kyank U, Fischer-Brandies H, Gassling V, Tzaribachev N. Reliability of clinical symptoms in diagnosing temporomandibular joint arthritis in juvenile idiopathic arthritis. J Rheumatol 2014;41:1871-7.
11. Muller L, Kellenberger CJ, Cannizzaro E, Ettlin D, Schraner T, Bolt IB, et al. Early diagnosis of temporomandibular joint involvement in juvenile idiopathic arthritis: a pilot study comparing clinical examination and ultrasound to magnetic resonance imaging. Rheumatology 2009;48:680-5.

12. Stoustrup P, Resnick CM, Pedersen TK, Abramowicz S, Michelotti A, Kuseler A, et al. Standardizing terminology and assessment for orofacial conditions in juvenile idiopathic arthritis: international, multidisciplinary consensus-based recommendations. J Rheumatol 2019;46:518-22.

13. Stoustrup P, Twilt M, Spiegel L, Kristensen KD, Koos B, Pedersen TK, et al. Clinical orofacial examination in juvenile idiopathic arthritis: international consensus-based recommendations for monitoring patients in clinical practice and research studies. J Rheumatol 2017;44:326-33.

14. Foeldvari I, Tzaribachev N, Cron RQ. Results of a multinational survey regarding diagnosis and treatment of the temporomandibular joint involvement in juvenile idiopathic arthritis. Pediatr Rheumatol Online J 2014;12:6.

15. Stoll ML, Good J, Sharpe T, Beukelman T, Young D, Waite PD, et al. Intra-articular corticosteroid injections to the temporomandibular joints are safe and appear to be effective therapy in children with juvenile idiopathic arthritis. J Oral Maxillofac Surg 2012;70:1802-7.

16. Stoustrup P, Kristensen KD, Verna C, Kuseler A, Pedersen TK, Herlin T. Intra-articular steroid injection for temporomandibular joint arthritis in juvenile idiopathic arthritis: a systematic review on efficacy and safety. Semin Arthritis Rheum 2013;43:63-70.

17. Resnick CM, Pedersen TK, Abramowicz S, Twilt M, Stoustrup PB. Time to reconsider management of the temporomandibular joint in juvenile idiopathic arthritis. J Oral Maxillofac Surg 2018;76:1145-6.

18. Lochbuhler N, Saurenmann RK, Muller L, Kellenberger CJ. Magnetic resonance imaging assessment of temporomandibular joint involvement and mandibular growth following corticosteroid injection in juvenile idiopathic arthritis. J Rheumatol 2015; 42:1514-22.

19. Stoll ML, Amin D, Powell KK, Poholek CH, Strait RH, Aban I, et al. Risk factors for intraarticular heterotopic bone formation in the temporomandibular joint in juvenile idiopathic arthritis.

J Rheumatol 2018;45:1301-7.

20. Stoll ML, Morlandt AB, Teerawattanapong S, Young D, Waite PD, Cron RQ. Safety and efficacy of intra-articular infliximab therapy for treatment-resistant temporomandibular joint arthritis in children: a retrospective study. Rheumatology 2013;52:554-9.

21. Bollhalder A, Patcas R, Eichenberger M, Müller L, Schroeder-Kohler S, Saurenmann RK, et al. Magnetic resonance imaging followup of temporomandibular joint inflammation, deformation, and mandibular growth in juvenile idiopathic arthritis patients receiving systemic treatment. J Rheumatol 2020;47:909-16.

22. Stoustrup P, Pedersen TK, Nørholt SE, Resnick CM, Abramowicz S. Interdisciplinary management of dentofacial deformity in juvenile idiopathic arthritis. Oral Maxillofac Surg Clin North Am 2019 Nov 4 (E-pub ahead of print).

J Rheumatol 2020;47:793-5; doi:10.3899/jrheum.191169 